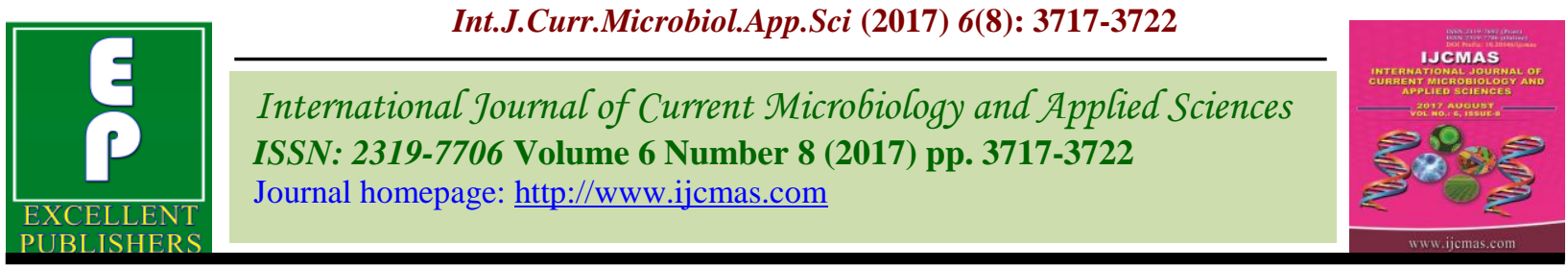

Original Research Article

https://doi.org/10.20546/ijcmas.2017.608.449

\title{
Seaweed Kappaphycus Extract Proliferation in Mesenchymal Stem Cells and Bread as its Delivery Vehicle
}

\author{
S. Priya ${ }^{1 *}$, V. Perasiriyan ${ }^{2}$, A. Mangala Gowri ${ }^{3}$ and K. Ambashankar ${ }^{4}$ \\ ${ }^{1}$ Department of Food Science and Technology, ${ }^{2}$ Department of Food Engineering, College of \\ Food and Dairy Technology, Tamil Nadu Veterinary and Animal Sciences University, \\ Chennai- 600 052. Tamil Nadu, India \\ ${ }^{3}$ Centre for Stem Cell Research and Regenerative Medicine, Tamil Nadu Veterinary and Animal \\ Sciences University, Chennai- 600 007, Tamil Nadu, India \\ ${ }^{4}$ ICAR- Central Institute of Brackish Water Aquaculture, Chennai, Tamil Nadu, India \\ *Corresponding author
}

\section{A B S T R A C T}

With the emergence of fortified foods there is a worldwide increase in health alertness and awareness in herbal alternatives. Adoption of fortification techniques enable to enhance

Keywords the nutritional quality of the product. Common foods such as bread and biscuits can be fortified with enriched herbal extracts. Bread is considered as an excellent source of

Seaweed, Proliferation, Mesenchymal stem cells, Fortification, Bread.

Article Info Accepted: 21 June 2017 Available Online: 10 August 2017 energy, and an adequate source of protein, essential minerals and other micronutrients. Seaweed, being an untapped source of plant protein and excellent preventive medium against cardiovascular diseases, was enriched in bread at 3,6 and 9 per cent incorporation level. In vitro studies provide a basis for comparing cytotoxicity data across species. As NRC recommends on the testing the dietary ingredients in target species, herbal extracts were tested in goat bone derived progenitor cells. The herbs at the highest concentration of $100 \mu \mathrm{g} / \mathrm{mL}$ tested in proliferation and radical scavenging analysis were found to be safe for use. The seaweed did not show any significant adverse effects on the liveability of cultured cells during the observation period. Supplementation of bread with $3 \%$ showed a highest acceptability among the fortified breads. Thus, cereal-based products enriched with seaweed can be used as a vehicle for the delivery of bioactive compounds at suitable levels that provide health benefits for increased well-being. The present study investigated the effect of selected herbs with profound effect to maintain homeostasis in proliferation and radical scavenging activity on tissue progenitor cells.

\section{Introduction}

Baked products are one of the most widely consumed foods in the world and therefore have great potential as vehicles for bioactive ingredients delivery (Kadam and Prabhasankar, 2010). Many bread companies enrich their baked products with folic acid (Crider et al., 2011). Increasing the protein, nutritional and health benefits of bread is one strategy for improving consumer nutrition and is not a novel concept. The nutritional qualities of breads were improved by the addition of skim milk powder and soy proteins to breads (Mostafa et al., 1982). The quality of the bread gets affected when the storage period is increased (He and Hooseney, 1990). Omega-3 enriched bread was used as a 
delivery vehicle for EPA and DHA. This is delivered in the form of microencapsulated tuna oil at levels of $10 \mathrm{mg}$ of long chain n-3 polyunsaturated fatty (PUFA) oils per slice (Yep et al., 2002). Baked products can provide consumers with high quality omega-3 breads with higher contents of EPA and DHA than the average functional food products. Omega-3 fortified bread was launched in 2009 to increase the health benefits of school children. Other baked goods such as biscuits enriched with omega-3 fatty acids to impart health benefits to the consumer. Seo et al., (2006) investigated the effects of 31 types of seaweed on the proliferation of mouse spleen and thymus cells. It was shown that the extracts of three seaweed plants exhibited significantly positive effects on the survival of mouse spleen and thymus cells in vitro. However, the methanolic extracts of seaweeds exhibited significant cell proliferation properties in both spleen and thymus cells. In the present study, bone marrow mesenchymal stem cells were used for the proliferation analysis and radical scavenging activity of Kappaphycus spp.

\section{Materials and Methods}

\section{In vitro sea weed extract analysis in mammalian stem cells}

Goat bone marrow derived stem cells were obtained as per the previously standardized protocol (Gowri et al., 2007). The proliferation analysis and radical scavenging activity analysis of seaweed extract at various concentrations ranging from $20 \mu \mathrm{g} / \mathrm{mL}$ to $100 \mu \mathrm{g} / \mathrm{mL}$ was done.

\section{Bread preparation}

Wheat flour, Sugar, Salt, egg, Yeast (Saf yeast company Pvt. Ltd., Mumbai, India), Bread improver (Venus Essence Pvt Ltd, Chennai), Water/whole milk, Milk solids,
Soya flour, Shortening (oil), Ascorbic acid (Vitamin C). The seaweed (Kappaphycus spp.,) was obtained from Central Institute of Brakish water Aquaculture, Chennai, India.

\section{Preparation of the herbal bread}

Dried ingredients were incorporated in bread. Bread mix was prepared by adding the standard ingredients in referred quantities (sugar, salt, yeast, vegetable fat, soya flour, bread improver, vegetable oil, SMP, and dried herbal ingredient was added to the wheat flour) and were mixed together in a planetary mixer. The dry ingredients, shortening and the activated yeast were added in a bowl along with water and then kneaded until the dough was elastic and the required consistency was reached. After this, the dough was rounded and kept in a bowl for the first proofing at room temperature $\left(30^{\circ} \mathrm{C}\right)$ for about $40 \mathrm{~min}$. The bowl was covered with a wet cloth to maintain a relative humidity of $80-90 \%$. After the first proofing, the dough was punched and worked lightly so that the excess gas could escape and the gas cells are redistributed. Dough (450g) was placed in aluminium alloy toast mould set of three (dimensions: $450 \mathrm{~g}$ $192 * 110 * 110 \mathrm{~mm}$, three units joined in one set). The dough was then shaped to fit lightly in greased bread moulds. The dough was again kept for the final proofing for about one hour at $40 \pm 1^{\circ} \mathrm{C}$. After baking, the prepared bread samples were cooled for about one hour at room temperature for further analysis (Fig. $3)$.

\section{Results and Discussion}

The seaweed extract exhibited significant cell proliferation properties in bone marrow derived mesenchymal stem cells and showed significant radical scavenging potential in the present research (Figs. 1a, 1b and 2). Mao et al., (2006) and Lau et al., (2014) investigated on seaweeds such as Kappaphycus alvarezii 
and Kappaphycus striatum and found that the methanolic, acetonic and aqueous extracts showed to have antioxidant, antimicrobial and antitumor properties and proliferative activity which was found to be similar to our research. At present, many of the biochemical substances found in medicinal herbs have shown effectiveness in treating bone fracture. Furthermore, the side effects of natural products are considered less harmful than those of conventional medicine. The use of medicinal herbs in the treatment of bone fractures is due to enhancement of osteoblast proliferation. Zeng et al., (2008) investigated on Si-wu decoction (SDE), a classic prescription in traditional Chinese medicine and reported that it promoted proliferation of rat marrow derived mesenchymal stem cells which supports our results. Fayaz et al., (2005) showed that antioxidant activity of Kappaphycus alvarezii (K. alaverzii) prevents the oxidative damage in living organisms. Mao et al., (2006) and De et al., (2012) investigated on the acceptability of Ascophyllum nodosum enriched bread and measured its effect on energy intake and nutrient absorption. Results indicated that it is acceptable to incorporate seaweed (A. nodosum) into a staple food such as bread at concentrations of up to $4 \%$ per $400 \mathrm{~g}$ wholemeal loaf which was similar to the result obtained showing that $3 \%$ showed the maximum acceptability among the other combination (Fig. 4). Fitzgerald et al., (2014) examined the textural and sensory effects of bread formulated using a Palmaria palmate protein hydrolysate with in vitro renin inhibitory properties. Four formulations were examined; a wheat flour control bread, a control bread containing $4 \% \quad P$. palmate protein hydrolysate, a buckwheat bread consisting of a blend of $70 \%$ wheat: $30 \%$ buckwheat, and a fourth formulation of the buckwheat bread containing $4 \%$ P. palmata hydrolysate.
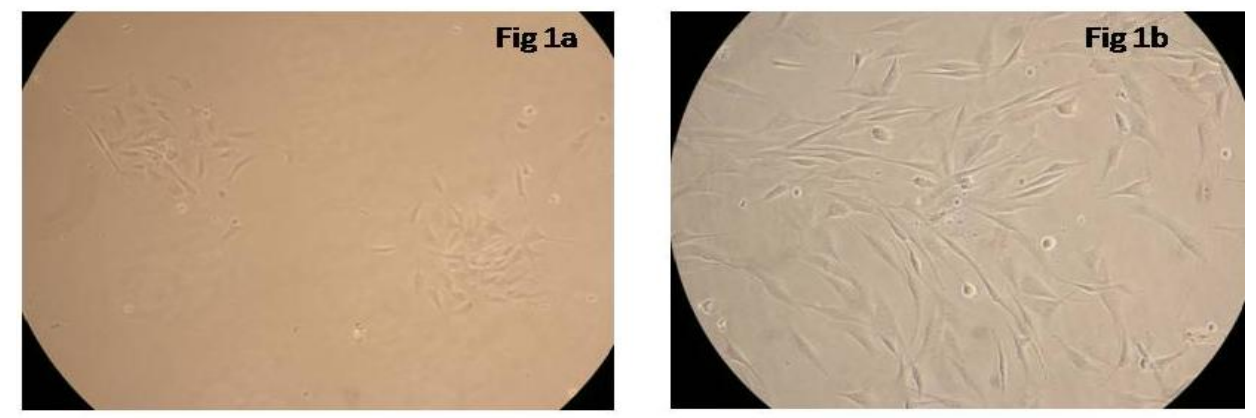

Fig 1a Representative microphotograph of cultured gMSC on $3^{\text {rd }}$ day (200x)

Fig 1b Representative microphotograph of gMSC on $7^{\text {th }}$ day (200x)

Fig.2 Radical scavenging activity of the seaweed

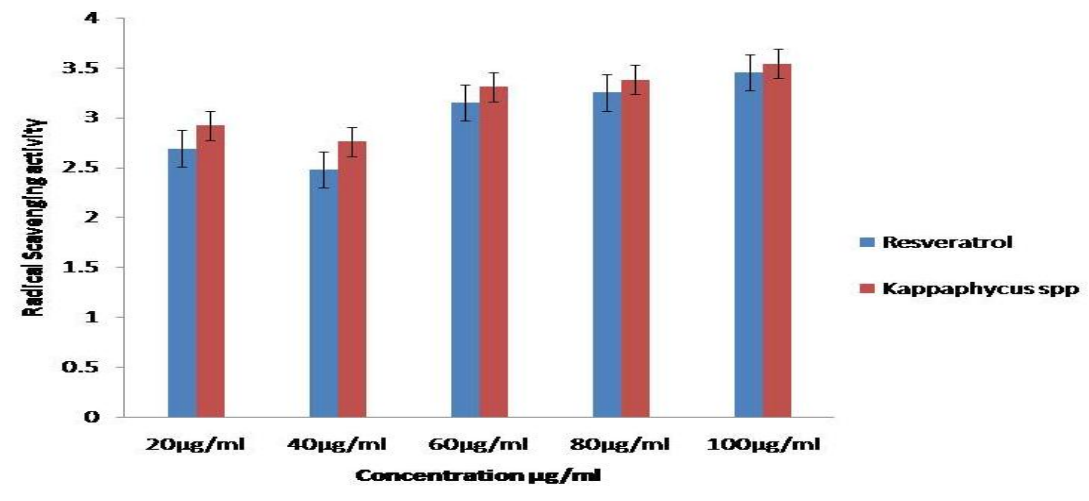




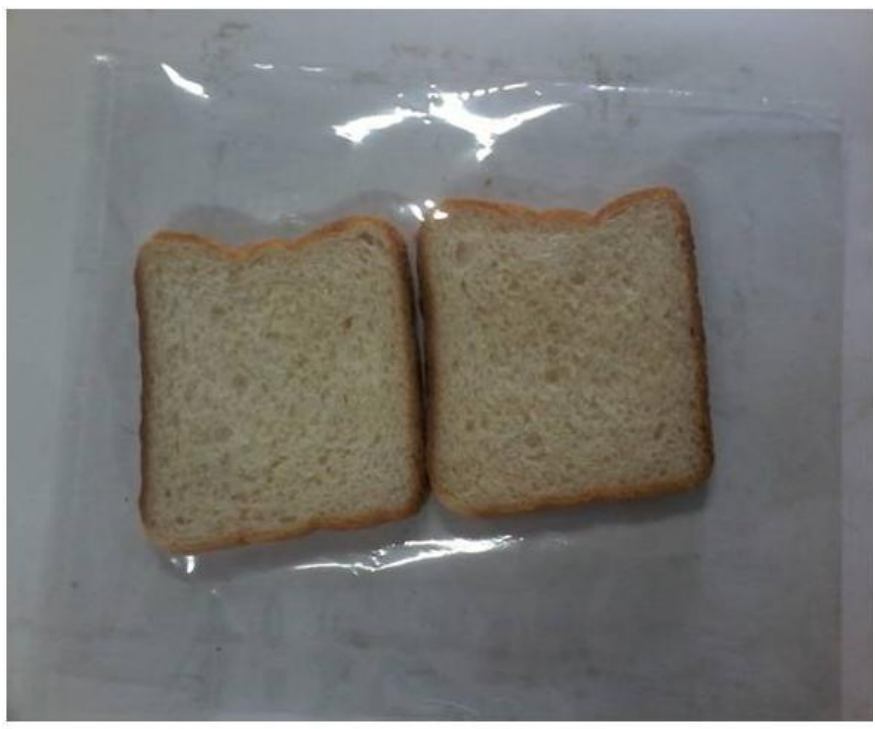

Fig 3: Development of seaweed incorporated bread

Fig.4 Sensory evaluation of Seaweed bread

\section{Sensory evaluation of seaweed bread}

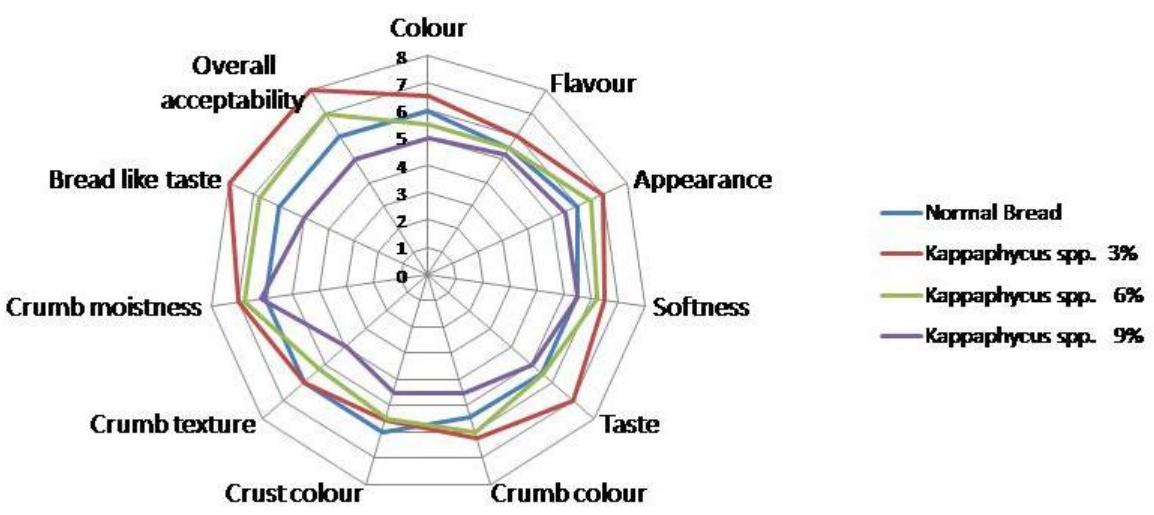

The volume, colour, texture profile, moisture, crumb structure, sensory attributes and renin inhibitory activity of all four baked breads were evaluated. Smertina et al., (2016) evaluated on the nutritional value of bakery products incorporated with sea algae.

Studies have shown that resveratrol promotes the survival of mesenchymal stem cells (Pinarli et al., 2013), enhanced the proliferation and osteoblastic differentiation of human bone marrow-derived mesenchymal stem cells (Dai et al., 2007) which coincides with the present report where the effect of resveratrol showed a significant effect on the proliferation of MSCs in a concentration dependent manner compared to synergistic activity of the herbs on gMSC cells. According to the literature, sea algae contain unique biologically active substances (BAS). It was shown that incorporation of sea algae into the flour contributed to the increase in quality of baked bread and gives it therapeutic and prophylactic properties. 
The health value of bread was increased through the addition of a seaweed protein hydrolysate. Cellular proliferative potential of the seaweed were established in goat bone marrow mesenchymal stem cells that mimic the in vivo mammalian system closer than the existing testing platform. As NRC recommends on the testing the dietary ingredients in target species, seaweed extracts were tested in goat bone marrow derived mesenchymal stem cells. The herbs at the highest concentration of $100 \mu \mathrm{g} / \mathrm{mL}$ tested in proliferation and radical scavenging analysis were found to be safe for humans. Herbal fortification of foods is based on the notion that "Food thy Medicine" which can improve the functional quality of foods and the ability to combat diseases, promoting well-being in animals and humans. The present study concluded the effect of seaweed Kappaphycus spp., with profound effect to maintain homeostasis by promoting healthy proliferation and radical scavenging activity on tissue stem cells.

\section{References}

Kadam, S.U and P. Prabhasankar, 2010. Marine foods as functional ingredients in bakery and pasta products- A review. Food Research International. 43:1975-1980.

Crider, K. S., L.B. Bailey, L. B and R.J.Berry, 2011. Folic acid food fortification its history, effect concerns and future directions. Nutrients. 3: 370-384.

Mostafa, M. K., A.S. Hamed and Y.H. Foda, 1982. Enrichment of wheat flour with dry skim milk and dry buttermilk and its effect on the baking quality. Egyptian Journal of Food Science. 8: 33-39.

He, H and R.C. Hoosney, 1990. Changes in Bread Firmness and Moisture during Long-Term Storage. Cereal Chemistry. 67(6):603-605.
Yep, Y. L., D. Li, N.J. Mann, O. Bode and A. Sinclair, 2002. Bread enriched with microencapsulated tuna oil increases plasma docosahexaenoic acid and total omega-3 fatty acids in humans. Asia Pacific Journal of Clinical Nutrition. 11: 285-291.

Lau, T.Y., D.F. Vittal, C.S.Y. Chew and W.T.L. Yong, 2014.Anti-proliferative potential of extracts from Kappaphycus Seaweeds on HeLa Cancer Cell Lines. Sains Malaysiana. 43(12): 1895-1900.

Pinarli, F.A., N.N. Turan, F.G. Pinarli, A. Okur, D. Sonmez, T. Ulus, A. Oguz, C. Karadeniz, T.

Delibasi,2013.Resveratrol and adiposederived mesenchymal stem cells are effective in the prevention and treatment of doxorubicin cardiotoxicity in rats. Pediatric Hematology and Oncology. 30: 226-238.

Seo, Y., S. Kang, H. Lee, Y. A. Kim, H.J. Youn, B.J. Lee and H. Chung, 2006. In vitro Screening of Seaweed extract on theProliferation of Mouse Spleen and Thymus Cell. Biotechnology and Bioprocess Engineering. 11:160-163

Fayaz, M., K.K. Namitha, K.N.C. Murthy, M.M. Swamy, R. Sarada and K. Salma, 2005. Chemical composition, iron bioavailability, and antioxidant activity of Kappaphycus alvarezii (Doty) Doty. Journal of Agricultural and Food Chemistry. 53: 792-797.

Fitzgerald, C., E. Gallagher, L. Doran, M. Auty, J. Prieto and M. Hayes, 2014. Increasing the health benefits of bread: Assessment of the physical and sensory qualities of bread formulated using a renin inhibitory Palmariapalmata protein hydrolysate. LWT - Food Science and Technology.56: 398-405.

Dai, Z., Y. Li, L.D. Quarles, T. Song and W. Pan, 2007. Resveratrol enhances 
proliferation and osteoblastic differentiation in human mesenchymal stem cells via ER-dependent ERK1/2 activation. Phytomedicine. 14: 806814.

Mao, W., X. Zang, Y. Li and H. Zhang, 2006. Sulfated polysaccharides from marine green algae Ulva conglobata and their anticoagulant activity. Journal of Applied Phycology. 18: 9-14.
Zeng, H.P., T.T. Wang, W. Chen, C.Y. Wang, D.F. Chen and J.G. Shen, 2008 . Characterization of chemical components in extracts from Si-wu decoction with proliferation-promoting effects on rat mesenchymal stem cells. Bioorganic and Medicinal Chemistry. 16:5109-5114.

\section{How to cite this article:}

Priya, S., V. Perasiriyan, A. Mangala Gowri and Ambashankar, K. 2017. Seaweed Kappaphycus Extract Proliferation in Mesenchymal Stem Cells and Bread as Its Delivery Vehicle. Int.J.Curr.Microbiol.App.Sci. 6(8): 3717-3722.

doi: https://doi.org/10.20546/ijcmas.2017.608.449 